\title{
EFFECT OF INTRAVENOUS VERSUS INTRATHECAL DEXMEDETOMIDINE ON CHARACTERISTICS OF HYPERBARIC BUPIVACAINE SPINAL ANESTHESIA IN LOWER LIMB SURGERY
}

\author{
LAXMAN K SENAPATI ${ }^{1}$, PRIYADARSINI SAMANTA ${ }^{2}$
}

${ }^{1}$ Department of Anaesthesia, Kalinga Institute of Medical Sciences, Bhubaneswar, Odisha, India. ${ }^{2}$ Department of Physiology, Kalinga Institute of Medical Sciences, Bhubaneswar, Odisha, India. Email: dr.priyasamanta@gmail.com

Received: 22 March 2018, Revised and Accepted: 16 April 2018

\begin{abstract}
Objectives: Dexmedetomidine was shown to prolong the duration of spinal anesthesia and enhance post-operative analgesia. The aim of the study was to compare the effect of intravenous (IV) versus intrathecal (IT) administration of dexmedetomidine on bupivacaine spinal anesthesia in patients undergoing lower limb surgery.

Methods: A prospective randomized controlled study was conducted during the year 2014-15.60 American Society of Anesthesiologists physical status I-II aged 18-60 years scheduled for lower limb surgery under spinal anesthesia were assigned randomly to two groups: (1) IT group (IT group) $(\mathrm{n}=30)$ patients received $3 \mathrm{ml}$ of $0.5 \%$ hyperbaric bupivacaine and $5 \mu \mathrm{g}$ of dexmedetomidine intrathecally $(100 \mu \mathrm{g} / 1 \mathrm{ml}$ ampoule drawn in $40 \mathrm{IU} / \mathrm{ml}$ insulin syringe making $5 \mu \mathrm{g}=2 \mathrm{IU}=0.05 \mathrm{ml}$ ) and (2) IV group (IV group) ( $\mathrm{n}=30$ ) received $3 \mathrm{ml}$ of $0.5 \%$ hyperbaric bupivacaine and $0.05 \mathrm{ml}$ of normal saline intrathecally followed 5 min later by IV dexmedetomidine $0.5 \mu \mathrm{g} / \mathrm{kg}$ by infusion pump over $10 \mathrm{~min}$ as a single dose.

Results: The IT group had a statistically significantly earlier sensory onset to T10 and shorter time from injection to highest sensory level (p $<0.001$ ). The regression times of two dermatomes, regression time to S1 dermatome and time to reach Bromage 3 motor block were significantly less in the IT group, whereas regression time to Bromage 0 was prolonged $(\mathrm{p}<0.001)$. The IT group showed a significantly longer time to the use of rescue analgesia and less analgesic consumption in first $24 \mathrm{~h}$ than the IV group $(\mathrm{p}<0.001)$. Furthermore, the intensity of pain was significantly less in the IT group as compared to IV group $(\mathrm{p}<0.001)$. Compared with IV group, the IT group had low sedation score, fewer overall side effects, which was statistically not significant $(\mathrm{p}>0.05)$.
\end{abstract}

Conclusion: In bupivacaine spinal anesthesia for limb surgeries, dexmedetomidine, when administered intrathecally, has greater augmentation to sensory and motor block, more hemodynamic stability, better analgesic properties, and fewer overall side effects compared to the IV route of administration.

Keywords: Bupivacaine, Spinal anesthesia, Dexmedetomidine, Intravenous, Intrathecal, Limb surgery.

(c) 2018 The Authors. Published by Innovare Academic Sciences Pvt Ltd. This is an open access article under the CC BY license (http://creativecommons. org/licenses/by/4. 0/) DOI: http://dx.doi.org/10.22159/ajpcr.2018.v11i7.26096

\section{INTRODUCTION}

Spinal anesthesia is a form of regional anesthesia which involves injection of a local anesthetic into the subarachnoid space and commonly used for lower abdominal, perineal, and lower limb surgery. It provides several advantages such as ease of administration, low cost, decreased risk of pulmonary aspiration, elimination of the need for intubation, reduced intraoperative blood loss, decrease in perioperative cardiac dysrhythmia, post-operative hypoxic episode, and also arterial and venous thrombosis [1-3]. Various adjuvants such as phenylephrine, epinephrine, clonidine, magnesium sulfate, neostigmine, and opioids have been used to prolong the duration of action of bupivacaine $[4,5]$.

Dexmedetomidine is a highly selective $\alpha 2$-adrenoceptor agonist which produces dose-dependent sedation and analgesia without respiratory depression [6-9]. It has been reported to prolong the duration of local anesthetics by different routes of administration $[10,11]$. Studies have shown that intravenous (IV) and intrathecal (IT) dexmedetomidine have prolonged the duration of spinal anesthesia and enhanced post-operative analgesia $[10,12]$. Kanaji et al. have reported that when dexmedetomidine was added to IT bupivacaine, it resulted in prolongation of the duration of spinal anesthesia [5]. Dexmedetomidine also lengthened the duration of spinal anesthesia when it was given intravenously before spinal anesthesia [13] or as a loading dose followed by continuous infusion during surgery [14]

In the present study, we aimed to compare the effect of IV versus IT administration of dexmedetomidine on characteristics of hyperbaric bupivacaine spinal anesthesia in patients undergoing lower limb surgery which has been sparsely documented.

\section{METHODS}

\section{Patients}

The sample size was calculated to detect an increase in $37 \mathrm{~min}$ in the two dermatomes sensory regression time (based on the findings of a previous study) [15], and it was determined as 26 for each group considering $\alpha$ error probability as 0.05 with power of the study $90 \%$. With the approval from the Institutional Ethical Committee of S.C.B Medical College, Cuttack and after obtaining written informed consent of patients, a prospective randomized controlled study was conducted during the year 2014-2015. A total of 60 patients classified as American Society of Anesthesiologists (ASA) I or II, of either sex, aged 18-60 years scheduled for lower limb extremity surgery under spinal anesthesia were enrolled in this study. Exclusion criteria were known allergy to any of the test drugs, contraindication to spinal anesthesia, obese patients (body mass index $>30$ ), height of patient $>180 \mathrm{~cm}$ or $<150 \mathrm{~cm}$, patients with significant cardiovascular, pulmonary, hepatic, renal, neurological and psychological disease, recent use of any analgesics, sedative drugs or antidepressants, and history of alcohol abuse.

\section{Study drugs}

All patients were assigned randomly using a computer-generated randomized code into two groups: (1) IT group (IT group) $(n=30)$ patients received $3 \mathrm{ml}$ of $0.5 \%$ hyperbaric bupivacaine and $5 \mu \mathrm{g}$ of 
dexmedetomidine intrathecally $(100 \mu \mathrm{g} / 1 \mathrm{ml}$ ampoule drawn in $40 \mathrm{IU} / \mathrm{ml}$ insulin syringe making $5 \mu \mathrm{g}=2 \mathrm{IU}=0.05 \mathrm{ml}$ ) and (2) IV group (IV group) $(\mathrm{n}=30)$ received $3 \mathrm{ml}$ of $0.5 \%$ hyperbaric bupivacaine and $0.05 \mathrm{ml}$ of normal saline intrathecally followed $5 \mathrm{~min}$ later by IV dexmedetomidine $0.5 \mu \mathrm{g} / \mathrm{kg}$ by infusion pump over $10 \mathrm{~min}$ as a single dose. The study drugs were prepared by an anesthetist who was not involved in the study, stored at room temperature in unlabeled syringes, and used within $30 \mathrm{~min}$ after preparation. Both the anesthetist and the post-anesthesia care unit (PACU) nurse who was involved in the study were blinded to patients' groups.

\section{Anesthetic management}

A full assessment of history, clinical examination, and revision of investigations was conducted preoperatively for all patients. Baseline vital signs such as blood pressure, heart rate (HR), oxygen saturation by pulse oximetry $\left(\mathrm{SpO}_{2}\right)$, and respiratory rate were recorded. All patients were kept nil per oral overnight. Patients were preloaded with Ringer's lactate solution $15 \mathrm{ml} / \mathrm{kg}$ after IV insertion of $18 \mathrm{G}$ cannula in the operating room. Under a sterile technique, spinal anesthesia was performed with the patient in sitting position with 25G Quincke needle in L3-L4 intervertebral space using midline approach. The time of spinal injection was considered time zero (T0). The IV drug regimen was started according to the group to which patients were assigned. Oxygen (2-4 l/min) was supplied by a nasal cannula. Monitoring included continuous ECG, non-invasive blood pressure, pulse oximetry, and HR.

\section{Assessment of parameters}

After successful spinal anesthesia, the vital signs were recorded at 2, 5, and every $5 \mathrm{~min}$ in the operation room and every $15 \mathrm{~min}$ in the PACU. Hypotension was defined as more than $25 \%$ decrease in mean arterial pressure (MAP) from the baseline and was treated with fluid boluses and IV injection of $6 \mathrm{mg}$ ephedrine. Bradycardia was defined as $\mathrm{HR}<50$ beats/min and treated with IV injection of $0.6 \mathrm{mg}$ atropine. Hypoxia was defined as oxygen saturation value below $90 \%$ and was treated with $\mathrm{O}_{2}$ face mask $6 \mathrm{~L} / \mathrm{min}$. The onset time (time required to reach loss of sensation at the level of T10 dermatome) and time to reach maximum dermatomal loss of sensation were noted. Assessment of motor block was performed using the modified Bromage scale [16]. Bromage 0: The patient is able to move the hip, knee, and ankle; Bromage 1: The patient is unable to move the hip but able to move the knee and ankle; Bromage 2: The patient is unable to move the hip and knee but able to move the ankle; and Bromage 3: The patient is unable to move the hip, knee, and ankle. The time to reach Bromage 3 motor block was recorded before surgery and the regression time to Bromage 0 was recorded after surgery. Patient's motor power and sensation to cold using alcohol solution up to T10 dermatome were examined in both the lower extremities. Another investigator who was blinded to the study assessed the sensory level at midclavicular line bilaterally for each patient by a pinprick test using a blunt $25 \mathrm{G}$ needle. All durations were calculated considering the time of spinal injection as time zero. After performing the spinal block, the level of sensory and motor block was checked every 2 min until the maximum level of block was achieved and at 5 min interval subsequently. In the PACU, sensory level and Bromage scale were recorded every 15 min until patient's discharge.

The level of sedation was evaluated intraoperatively and postoperatively every 15 min using Ramsey level of sedation scale [17]: (1) Patient anxious, agitated, or restless, (2) patient cooperative, oriented, and tranquil alert, (3) patient responds to commands, (4) asleep, but with brisk response to light glabellar tap or loud auditory stimulus, (5) asleep, sluggish response to light glabellar tap or loud auditory stimulus, and (6) asleep, no response.

Postoperatively, pain was assessed using visual analog scale (VAS) ranging from 0 to $10(0=$ no pain, $10=$ the most severe pain $)$ initially every hourly for $2 \mathrm{~h}$, then every 2 hourly for next $8 \mathrm{~h}$, then every 4 hourly till $24 \mathrm{~h}$. Total duration of analgesia was defined as the time from administration of subarachnoid block until first complains of pain (VAS >4). Intramuscular injection of $75 \mathrm{mg}$ of diclofenac sodium was used as rescue analgesic. The development of any side effects including nausea, vomiting, headache, itching, shivering, respiratory, or cardiovascular events was recorded.

\section{Statistical analysis}

The data collected was tabulated and analyzed using SPSS (version 21.0; SPSS Inc., Chicago, IL, USA). Results were expressed as means and SDs, or numbers and percentages. Statistical analyses were performed using Student's t-test for parametric data and Chi-square test for nonparametric data. $\mathrm{p}<0.05$ was considered statistically significant and $\mathrm{p}<0.001$ was considered as highly statistically significant.

\section{RESULTS}

Both the patient groups were comparable in demographic characteristics, duration of surgery, and ASA physical status ( $p>0.05$ ) (Table 1). Pre-operative MAP and HR were similar in both the groups. There were no significant differences between groups in the MAP and HR values during $1^{\text {st }}$ hour after spinal anesthesia and $1^{\text {st }}$ hour in recovery room ( $p>0.05$ ) (Figs. 1 and 2 ).

\section{Spinal block characteristics}

The IT group had a statistically significantly earlier sensory onset to $\mathrm{T} 10(\mathrm{p}<0.001)$ and shorter time from injection to highest sensory level $(\mathrm{p}<0.001)$. The regression times of two dermatomes and regression time to S1 dermatome were significantly less in IT group as compared to IV group $(\mathrm{p}<0.001)$. The mean onset time to reach Bromage 3 motor block was significantly shorter in IT group $(\mathrm{p}<0.05)$, but the regression time to Bromage 0 was significantly prolonged in the IT group than in the IV group $(\mathrm{p}<0.001)$ (Table 2$)$.

\section{Analgesia, sedation, and adverse effects}

The IT group showed a significantly longer time to the use of rescue analgesia $(\mathrm{p}<0.001)$ and less analgesic consumption in first $24 \mathrm{~h}$ than the IV group $(\mathrm{p}<0.001)$. Furthermore, the intensity of pain (VAS score over $8 \mathrm{~h}$ ) was significantly less in IT group as compared to IV group $(\mathrm{p}<0.001)$. The sedation score was higher in IV group than the IT group, but this was statistically insignificant $(p>0.05)$. Compared with IV group, the IT group had fewer overall side effects, which was statistically not significant ( $p>0.05$ ) (Table 3$)$.

\section{DISCUSSION}

In the present study, we compared the effect of dexmedetomidine given by two different routes: IT or IV on bupivacaine spinal anesthesia. We observed that IT administration of dexmedetomidine enhanced the anesthetic properties of bupivacaine compared to intravenously

Table 1: Demographic characteristics of patients $(n=60)$

\begin{tabular}{llc}
\hline Parameters & Group IT (n=30) & Group IV (n=30) \\
\hline Age (years) & $42.21 \pm 3.8$ & $44.35 \pm 4.08$ \\
Sex (Male/Female) & $15 / 10$ & $18 / 07$ \\
Height (cm) & $168.3 \pm 8.6$ & $170.0 \pm 10.2$ \\
Weight (kg) & $65.13 \pm 13.4$ & $64.42 \pm 9.6$ \\
Duration of surgery (min) & $63.84 \pm 30.5$ & $69.40 \pm 40.34$ \\
ASA I/ASA II & $22 / 08$ & 0.551 \\
\hline
\end{tabular}

IT: Intrathecal, IV: Intravenous. Values are represented as mean \pm SD or number; $\mathrm{P}<0.05$ is considered as statistically significant. SD: Standard deviation, ASA: American

Society of Anesthesiologists 
administered dexmedetomidine. The time to reach T10 sensory block was significantly shortened, and the sensory regression time to S1 dermatome was significantly prolonged in IT group. Furthermore, the time to onset of motor block was significantly shorter in IT group, whereas the duration of motor block was significantly prolonged in this group. These findings are in consistency with the results of other studies $[15,18]$.

It has been reported that dexmedetomidine as a local anesthetic adjuvant prolongs the duration of both motor and sensory blockade produced by single injection neuraxial and peripheral nerve blockade $[19,20]$.

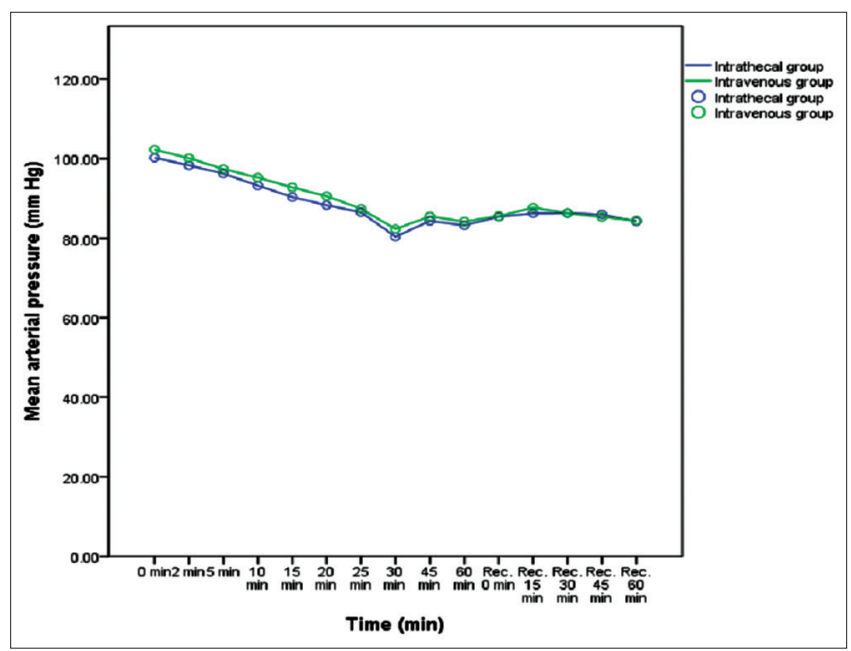

Fig. 1: Mean arterial pressure changes $(\mathrm{mmHg})$ between groups

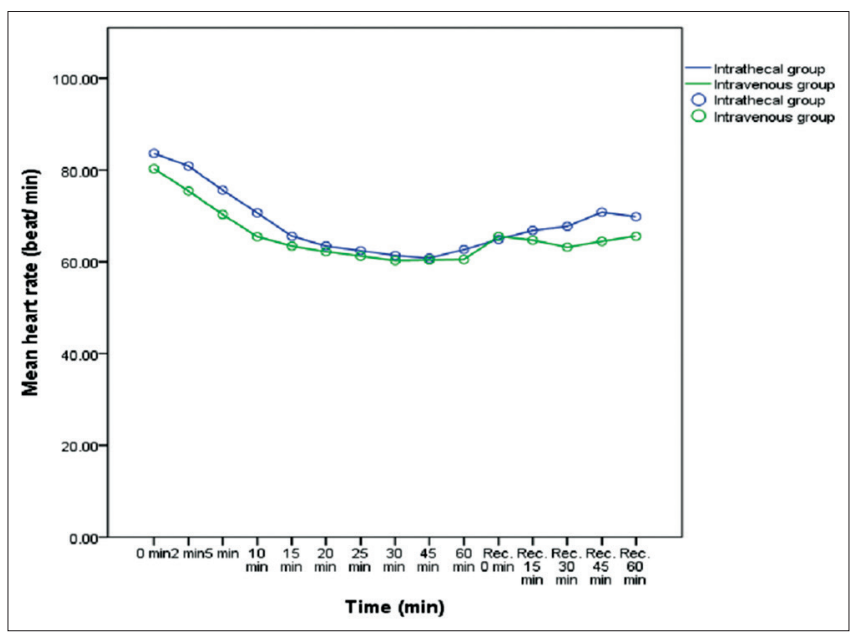

Fig. 2: Heart rate changes (beats/min) between groups
The mechanism is suggested to be an additive or synergistic effect by which IT [5] or IV [13] dexmedetomidine prolongs the motor and sensory block of the bupivacaine. IV dexmedetomidine acts through supraspinal action [21], whereas intrathecally it depresses the release of $\mathrm{C}$-fibers transmitters through binding to presynaptic $\mathrm{C}$ fibers and by hyperpolarization of postsynaptic dorsal horn neurons [22]. Several studies have reported that administration of dexmedetomidine intravenously $[12,23,24]$ or intrathecally $[5,25]$ has fastened the onset of sensory block and prolonged the duration of sensory and motor block.

The results of our study regarding the time of initiation to rescue analgesia, total analgesic consumption, and VAS score indicated that IT dexmedetomidine augmented the analgesic properties of bupivacaine and reduced the analgesic requirement as compared to IV dexmedetomidine. This suggests that the analgesic effect of $\alpha 2$ agonists may occur mainly at a spinal level. Due to high lipophilicity of dexmedetomidine, it is rapidly absorbed into the cerebrospinal fluid and binds to the spinal cord $\alpha 2$ adrenoceptor. It has been shown that IT administration of dexmedetomidine exerts potent antinociceptive effects in animals $[26,27]$. The $\alpha 2$ agonists act at three different sites such as brain and brainstem, spinal cord, and in peripheral tissues to induce analgesia. At the spinal cord level, stimulation of $\alpha 2$ receptors results in analgesia by different suggested mechanisms such as activation of the descending medullospinal noradrenergic pathways, reduction of the spinal sympathetic outflow at presynaptic ganglionic sites, interaction between opioids and $\alpha 2$ agonists at the spinal cord level, and inhibition of release of substance $P$ in the nociceptive pathway $[18,28]$.

With respect to hemodynamics, HR and MAP values were comparable throughout the study period. The use of $\alpha 2$ agonists is most commonly associated with side effects such as bradycardia and hypotension, which is in agreement with our result. Both the side effects were more frequent in the IV group than the IT group. However, these differences were not statistically significant as in previous studies [18,29]. Shivering was absent in both groups in our study. Affifi et al. showed the antishivering property of the $\alpha 2$ adrenergic agents in their study [18]. Respiratory depression was not reported in either group and this finding is in accordance with results of other studies [18,30], which has also been validated by the results of our study. After spinal anesthesia, the incidence of nausea/vomiting has been reported between 0 and $18 \%$ in previous studies $[18,31]$. In contrast, no patient in our study developed nausea/vomiting.

The present study has few limitations; inclusion of a control group using bupivacaine only for spinal anesthesia would have added greater power to the study. Further, results of this study cannot be generalized to different types of patients, surgeries, or older age groups as the study focused on a smaller, specified group of patients conducted in a single institution.

\section{CONCLUSION}

In bupivacaine spinal anesthesia for limb surgeries, when used as an adjuvant IT dexmedetomidine is superior to IV dexmedetomidine.

Table 2: Characteristics of spinal block in patients $(n=60)$

\begin{tabular}{lll}
\hline Parameters & Mean \pm SD & p value \\
\cline { 2 - 3 } & Group IT (n=30) & Group IV (n=30) \\
\hline Time to reach T10 sensory block level (min) & $5.69 \pm 0.43$ & $6.35 \pm 0.41$ \\
Time from injection to highest sensory level (min) & $21.38 \pm 0.42$ & $22.97 \pm 0.45$ \\
Time to reach Bromage 3 motor block (min) & $5.18 \pm 1.13$ & $6.23 \pm 1.45$ \\
Time of two segment regression & $134.0 \pm 10.17$ & $98.80 \pm 11.56$ \\
From highest sensory level (min) & $319.23 \pm 24.11$ & 0.001 \\
Regression time to S1 & & $<0.001$ \\
Dermatome (min) & & $<0.001$ \\
Begression time to & $381.77 \pm 33.03$ & $213.1 \pm 21.16$
\end{tabular}

IT: Intrathecal, IV: Intravenous. Values are represented as mean \pm SD, $\mathrm{P}<0.05$ is considered as statistically significant. SD: Standard deviation 
Table 3: Analgesia, sedation, and adverse effects among patients $(n=60)$

\begin{tabular}{lll}
\hline Parameters & Group IT (n=30) & Group IV (n=30) \\
\hline Time of rescue analgesia (min) & $451.47 \pm 46.81$ & $227.67 \pm 33.11$ \\
Analgesic consumption in first 24 h & $1.12 \pm 0.23$ & $2.94 \pm 0.56$ \\
Sedation score over 2 h & $2.3 \pm 0.42$ & $2.6 \pm 0.74$ \\
VAS score over 8 h & $0.96 \pm 0.49$ & $1.65 \pm 0.74$ \\
Hypotension & $2(6.7)$ & $3(10.0)$ \\
Bradycardia & $0(0)$ & $1(3.3)$ \\
Shivering & 0 & 0.001 \\
Respiratory depression & 0 & 0.283 \\
Nausea and vomiting & 0 & 0.001 \\
\hline
\end{tabular}

IT: Intrathecal, IV: Intravenous. Values are represented as mean \pm SD or n (\%); P $<0.05$ is considered as statistically significant. SD: Standard deviation, VAS: Visual analog scale

IT administration of dexmedetomidine has greater augmentation to sensory and motor block, more hemodynamic stability, better analgesic properties, and fewer overall side effects compared to the IV routes of administration.

\section{ACKNOWLEDGMENTS}

Authors are very much thankful to the Head of Department of Anesthesia, S.C.B Medical College, Cuttack, Odisha, for their support and guidance.

\section{AUTHOR'S CONTRIBUTIONS}

Conceptualization of the study, data collection, and statistical analysis was done by Dr. Laxman Ku Senapati. Literature search and manuscript writing were done by Dr. Priyadarsini Samanta.

\section{CONFLICTS OF INTEREST}

The authors declared that they have no conflicts of interest.

\section{REFERENCES}

1. Naghibi K, Saryazdi H, Kashefi P, Rohani F. The comparison of spinal anesthesia with general anesthesia on the postoperative pain scores and analgesic requirements after elective lower abdominal surgery: A randomized, double-blinded study. J Res Med Sci 2013;18:543-8.

2. Petropoulos G, Siristatidis C, Salamalekis E, Creatsas G. Spinal and epidural versus general anesthesia for elective Cesarean section at term: Effect on the acid-base status of the mother and newborn. J Matern Neonatal Med 2003;13:260-6.

3. Attari MA, Mirhosseini SA, Honarmand A, Safavi MR. Spinal anesthesia versus general anesthesia for elective lumbar spine surgery: A randomized clinical trial. J Res Med Sci 2011;16:524-9.

4. Al-Mustafa M, Badran I, Abu-Ali H, Al-Barazangi B, Massad I, AlGhanem S. Intravenous dexmedetomidine prolongs bupivacaine spinal analgesia. Middle East J Anaesthesiol 2009;20:225-31.

5. Kanazi GE, Aouad MT, Jabbour-Khoury SI, Al Jazzar MD, Alameddine MM, Al-Yaman $\mathrm{R}$, et al. Effect of low-dose dexmedetomidine or clonidine on the characteristics of bupivacaine spinal block. Acta Anaesthesiol Scand 2006;50:222-7.

6. Khan ZP, Ferguson CN, Jones RM. Alpha-2 and imidazoline receptor agonists. Their pharmacology and therapeutic role. Anaesthesia 1999:54:146-65.

7. Maze M, Scarfini C, Cavaliere F. New agents for sedation in the intensive care unit. Crit Care Clin 2001;17:881-97.

8. Bansal T, Hooda S. Newer drugs in anaesthesia. Int J Pharm Pharm Sci 2012;4:668-70.

9. Kataria BC, Mehta DS, Chhaiya SB. Approval of new nervous system drugs in India compared with the us and eu. Int J Pharm Pharm Sci 2012;4:705-9.

10. Abdallah F, Brull R. Facilitatory effects of perineural dexmedetomidine on neuraxial and peripheral nerve block: A systematic review and metaanalysis. Br J Anaesth 2013;110:915-25.

11. Weinbroum A, Ben-Abraham R. Dextromethorphan and dexmedetomidine: New agents for the control of perioperative pain. Eur J Surg 2001;167:563-9.

12. Abdallah FW, Abrishami A, Brull R. The facilitatory effects of intravenous dexmedetomidine on the duration of spinal anesthesia: A systematic review and meta-analysis. Anesth Analg 2013;117:271-8.

13. Kaya FN, Yavascaoglu B, Turker G, Yildirim A, Gurbet A, Mogol EB, et al. Intravenous dexmedetomidine, but not midazolam, prolongs bupivacaine spinal anesthesia. Can J Anesth 2010;57:39-45.

14. Elcicek K, Tekin M, Kati I. The effects of intravenous dexmedetomidine on spinal hyperbaric ropivacaine anesthesia. J Anesth 2010;24:544-8.

15. Hamed A, Talaat S. Effect of intravenous versus intrathecal low-dose dexmedetomidine on spinal block in lower limb orthopedic surgery. Ain-Shams J Anaesthesiol 2014;7:205-10.

16. Bromage PR. A comparison of the hydrochloride and carbon dioxide salts of lidocaine and prilocaine in epidural analgesia. Acta Anaesthesiol Scand 1965;9:55-69

17. Ramsay M, Savege T, Simpson B, Goodwin R. Controlled sedation with alphaxalone-alphadolone. Br Med J 1974;2:656-9.

18. Afifi M, Mohammed A, Abdullah S, Ellisy K. Intrathecal versus intravenous dexmedetomidine in characteristics of bupivacaine spinal block in lower abdominal surgery. Menoufia Med J 2016;29:523-9.

19. Ammar A, Mahmoud K. Ultrasound-guided single injection infraclavicular brachial plexus block using bupivacaine alone or combined with dexmedetomidine for pain control in upper limb surgery: A prospective randomized controlled trial. Saudi J Anaesth 2012;6:109-14.

20. Gupta R, Bogra J, Verma R, Kohli M, Kushwaha JK, Kumar S. Dexmedetomidine as an intrathecal adjuvant for postoperative analgesia. Indian J Anaesth 2011;55:347-51.

21. Ebert TJ, Hall JE, Barney JA, Uhrich TD, Colinco MD. The effects of increasing plasma concentrations of dexmedetomidine in humans. Anesthesiology 2000;93:382-94.

22. Eisenach JC, De Kock M, Klimscha W. $\alpha 2$-Adrenergic agonists for regional anesthesia: A clinical review of clonidine (1984-1995). Anesthesiology 1996;85:655-74

23. Jung SH, Lee SK, Lim KJ, Park EY, Kang MH, Lee JM, et al. The effects of single-dose intravenous dexmedetomidine on hyperbaric bupivacaine spinal anesthesia. J Anesth 2013;27:380-4

24. Harsoor S, Rani D, Yalamuru B, Sudheesh K, Nethra S. Effect of supplementation of low dose intravenous dexmedetomidine on characteristics of spinal anaesthesia with hyperbaric bupivacaine. Indian J Anaesth 2013:57:265-9.

25. Kalso EA, Poyhia R, Rosenberg PH. Spinal Antinociception by dexmedetomidine, a highly selective $\alpha 2$ adrenergic agonist. Pharmacol Toxicol 1991;68:140-3.

26. Ishii $H$, Kohno $T$, Yamakura $T$, Ikoma M, Baba H. Action of dexmedetomidine on the substantia gelatinosa neurons of the rat spinal cord. Eur J Neurosci 2008;27:3182-90.

27. Calasans-Maia JA, Zapata-Sudo G, Sudo RT. Dexmedetomidine prolongs spinal anaesthesia induced by levobupivacaine $0.5 \%$ in guinea-pigs. J Pharm Pharmacol 2005;57:1415-20.

28. Kamibayashi T, Maze M. Clinical uses of $\alpha 2$-adrenergic agonists. Anesthesiology 2000;93:1345-9.

29. Niu XY, Ding XB, Guo T, Chen MH, Fu SK, Li Q. Effects of intravenous and intrathecal dexmedetomidine in spinal anesthesia: A meta-analysis. CNS Neurosci Ther 2013;19:897-904.

30. Hall JE, Uhrich TD, Barney JA, Arain SR, Ebert TJ. Sedative, amnestic, and analgesic properties of small-dose dexmedetomidine infusions. Anesth Analg 2000;90:699-705.

31. Carpenter RL, Caplan RA, Brown DL, Stephenson C, Wu R. Incidence and risk factors for side effects of spinal anesthesia. Anesthesiology 1992;76:906-16 